\section{Detection of pathogens from environmental samples for the evaluation of the health status of laboratory animals}

\author{
Andrea Cacciamali, Chiara Romano, \\ Martina Angela Checco, Riccardo Villa \\ IZSLER - Istituto Zooprofilattico \\ Sperimentale della Lombardia e \\ dell'Emilia Romagna - National \\ Reference Center for Alternative \\ Methods, Welfare and Care of the \\ Laboratory Animals, Brescia, Italy
}

\begin{abstract}
Pathogens present in the environment are the biggest source of diseases and epidemics in the breeding of laboratory animals. The presence of microorganisms, in fact, can critically influence the animal health status and consequently the validity and reproducibility of experimental data. In accordance with the 3 Rs principle, this study fits into the Refinement and Reduction concepts. The development of a health surveillance plan on environmental material from animal housing would have an important impact not only on maintaining an adequate state of health and on the generation of quality experimental data, but also on reducing the number of animals to be sacrificed.
\end{abstract}

\section{Introduction}

The protection of welfare and care of experimental animals is a bedrock in the field of health surveillance within the breeding. The development of molecular methods for the protection of animal health plays a key role, in consideration of the $3 R$ principle. ${ }^{1}$

FELASA guidelines $^{2}$ and the legislative decree $26 / 2014^{3}$ ratify that the implementation of a health-monitoring surveillance within the experimental breeding, because of the growing number of identified pathogens. Their presence in the environment is the biggest source of diseases and epidemics for the laboratory animals. It can critically influence the health status of the animals and consequently the validity and reproducibility of the experimental data.

This study is part of the concepts of Refinement and Reduction. In fact, thanks to the health screening of pathogens it is possible to obtain an improvement in animal and environmental conditions.
Furthermore, it is known from the scientific literature that the analysis on environmental samples (e.g. dust, water, sawdust, environmental swab) allows to obtain results similar to those performed on biological samples, with the aim of reducing the number of sentinel animals. ${ }^{4}$

Nowadays, a health monitoring program for the identification of viral agents from biological samples has been conducted in the IZSLER animal experimental facility, performing PCR and RT-PCR. The aim of the work was to refine the techniques for the extraction of nucleic acids from environmental matrices for the subsequent detection of any circulating pathogens with molecular biology techniques.

\section{Materials and Methods}

The environmental matrices to be analyzed were provided by IZSLER facility. In detail, samples of enrichment material, fur, sawdust and feces were collected. DNA extraction was performed with the following kits: DNeasy PowerSoil, RNeasy PowerSoil DNA Elution, AllPrep DNA/RNA PowerViral, DNA PowerSoil Pro, AllPrep DNA/RNA Mini while the RNA was extracted with RNeasy PowerSoil Total RNA, RNeasy PowerSoil DNA Elution, AllPrep DNA/RNA PowerViral, AllPrep DNA/RNA Mini. All kits were provided by QIAGEN (Milan, Italy). The extraction procedure was performed following the kit manuals or using the Qiacube Robotic Extraction System (QIAGEN) according to the manufacturer's instructions. Nucleic acids were quantified using QuantiFluor $^{\circledR}$ ONE dsDNA System and QuantiFluor $^{\circledR}$ RNA System with the Quantus $^{\mathrm{TM}} \quad$ Fluorometer (Promega). Furthermore, fur samples and enrichment materials were infected with DNA viruses, (Ectromelia Virus and Minute Virus of Mice) at known concentrations (101-102 DC50/ml), while the sawdust was infected with both viruses. DNA were extracted using the DNeasy PowerSoil Kit and the QIAamp DNA Mini Kit (QIAGEN), typically used for biological samples, after homogenization of the matrices. At the end of the extraction, the DNA was quantified and subjected to amplification by RealTime PCR for the detection of the MVM and ECTV viruses used for the infection.

\section{Results}

A first DNA and RNA extraction test on raw materials using the DNeasy PowerSoil,
Correspondence: Andrea Cacciamali, IZSLER - Istituto Zooprofilattico Sperimentale della Lombardia e dell'Emilia Romagna - National Reference Center for Alternative Methods, Welfare and Care of the Laboratory Animals, Brescia, Italy.

E-mail: andrea.cacciamali@izsler.it

Key words: Health surveillance; 3R's principle; rodents' breeding; environmental samples; molecular analysis.

Acknowledgments: This study was financially supported by the Italian Ministry of Health.

Disclosures: The authors declare no conflict of interest.

Conference presentation: This paper was presented at the Third Centro 3R Annual Meeting - L'era delle 3R: modelli in silico, in vitro e in vivo per promuovere la ricerca traslazionale 30 September - 1 October 2021, Evento online organizzato dal Politecnico di Torino.

Received for publication: 9 July 2021.

Accepted for publication: 7 September 2021.

This work is licensed under a Creative Commons Attribution NonCommercial 4.0 License (CC BY-NC 4.0).

CCopyright: the Author(s), 2021

Licensee PAGEPress, Italy

Biomedical Science and Engineering 2021; 4(s1):159 doi:10.4081/bse.2021.159

RNeasy PowerSoil DNA Elution and RNeasy PowerSoil Total RNA kits did not provide quantifiable nucleic acid concentrations. Then, after infecting fur samples, enrichment materials and sawdust with DNA viruses, the environmental matrices were extracted with DNeasy PowerSoil and QIAamp DNA Mini kits. The DNA concentrations are shown in Table 1. Additional samples were collected from the animal enclosure to test other kits provided by the manufacturer. The concentrations of the extracted nucleic acids are shown in Table 1.

\section{Discussion and Conclusions}

The preliminary data on environmental samples, showed that from the extraction performed with the DNeasy PowerSoil, RNeasy PowerSoil DNA Elution and RNeasy PowerSoil Total RNA kits it was not possible to obtain a sufficient quantity of nucleic acids, from the raw samples, useful for subsequent molecular investigations. Only after direct infection with high virus concentrations, a small amount of extracted DNA was obtained. The average $\mathrm{Cq}$ values 
Table 1. Concentration of DNA and RNA extracted from the environmental matrices with the different extraction kits.

\begin{tabular}{|c|l|c|c|c|c|}
\cline { 3 - 6 } \multicolumn{2}{c|}{} & $\begin{array}{c}\text { Enrichment } \\
\text { materials }\end{array}$ & Sawdust & Fur & Feces \\
\hline \multirow{5}{*}{ DNA } & QIAmp DNA Mini & $0.166 \mathrm{ng} / \mu \mathrm{l}$ & $0.269 \mathrm{ng} / \mu \mathrm{l}$ & $0.025 \mathrm{ng} / \mu \mathrm{l}$ & \\
\cline { 2 - 7 } & DNeasy PowerSoil & $0.083 \mathrm{ng} / \mu \mathrm{l}$ & $0.101 \mathrm{ng} / \mu \mathrm{l}$ & $<$ than blank & \\
\cline { 2 - 7 } & $\begin{array}{l}\text { All Prep DNA/RNA } \\
\text { PowerViral }\end{array}$ & $0.991 \mathrm{ng} / \mu \mathrm{l}$ & $11 \mathrm{ng} / \mu \mathrm{l}$ & $0.801 \mathrm{ng} / \mu \mathrm{l}$ & $\begin{array}{c}4.76 \\
\mathrm{ng} / \mu \mathrm{l}\end{array}$ \\
\cline { 2 - 7 } & DNA PowerSoil Pro & $1.31 \mathrm{ng} / \mu \mathrm{l}$ & $39 \mathrm{ng} / \mu \mathrm{l}$ & $0.576 \mathrm{ng} / \mu \mathrm{l}$ & $42 \mathrm{ng} / \mu \mathrm{l}$ \\
\cline { 2 - 7 } & $\begin{array}{l}\text { All Prep DNA/RNA } \\
\text { Mini kit }\end{array}$ & $20 \mathrm{ng} / \mu \mathrm{l}$ & $0.288 \mathrm{ng} / \mu \mathrm{l}$ & & $37 \mathrm{ng} / \mu \mathrm{l}$ \\
\hline \multirow{4}{*}{ RNA } & $\begin{array}{l}\text { All Prep DNA/RNA } \\
\text { PowerViral }\end{array}$ & $1.8 \mathrm{ng} / \mu \mathrm{l}$ & $18 \mathrm{ng} / \mu \mathrm{l}$ & $0.66 \mathrm{ng} / \mu \mathrm{l}$ & $23 \mathrm{ng} / \mu \mathrm{l}$ \\
\cline { 2 - 7 } & $\begin{array}{l}\text { All Prep DNA/RNA } \\
\text { Mini kit }\end{array}$ & $0.31 \mathrm{ng} / \mu \mathrm{l}$ & $0.51 \mathrm{ng} / \mu \mathrm{l}$ & & $15 \mathrm{ng} / \mu \mathrm{l}$ \\
\hline
\end{tabular}

obtained in Real-Time PCR from enrichment material and fur reflect the concentrations of DNA extracted with the different kits. Otherwise, the $\mathrm{Cq}$ values of the sawdust sample show an opposite trend, probably due to the complexity of the matrix.

The poor yield obtained after the extraction process may depend on several variables: a very low presence of viral agents in the environment, their different stability or the specificity of the commercial kits used.

With the AllPrep DNA/RNA PowerViral, DNA PowerSoil Pro and AllPrep DNA/RNA Mini kits it was possi- ble to extract both nucleic acids from the collected raw samples. This may be due to the increased sensitivity of the kits used or the collection of particularly dirty material; in fact the samples were collected prior to the weekly cleaning of the cages. However, it remains to be verified whether in the extracted DNA and RNA there is the presence of target viral material or whether the concentrations of nucleic acids, higher than in the previously used kits, depend on other types of contamination. For all these reasons, these preliminary results will be further investigated.

\section{References}

1. Russell WMS, Burch RL. The Principles of Humane Experimental Technique. London, UK: Methuen; 1959: pp. xiv +238 .

2. FELASA working group on revision of guidelines for health monitoring of rodents and rabbits, Mähler Convenor $\mathrm{M}$, Berard $\mathrm{M}$, et al. FELASA recommendations for the health monitoring of mouse, rat, hamster, guinea pig and rabbit colonies in breeding and experimental units. Lab Anim 2014;48:178-92.

3. Italian Legislative Decree 4 marzo 2014, n. 26. Attuazione della direttiva 2010/63/UE sulla protezione degli animali utilizzati a fini scientifici.

4. Buxton AS, Groombridge JJ, Griffiths RA. Seasonal variation in environmental DNA detection in sediment and water samples. PLoS One 2018;13:e0191737. 